Кононенко Е.И. «Благодеяния происходят из строительства»: круг заказчиков сельджукской мусульманской архитектуры Анатолии // Исламоведение. 2016. Т. 7. № 4. С. 58-68

ИСЛАМ И кУЛЬТУРА
Ответственный за рубрику Сефербе-

\begin{tabular}{|c|c|c|}
\hline УДК 297.1: 7.033 & Содержание статьи & Информация о статье \\
\hline DOI: 10.21779/2077- & Введение & Поступила в редакцию: 25.07.2016 \\
\hline $8155-2016-7-4-58-68$ & «Монументальная пропаганда» & Передана на рецензию: 26.07.2016 \\
\hline & Сельджуков Рума & Получена рецензия: 29.08.2016 \\
\hline Е.И. Кононенко & $\begin{array}{l}\text { Новая элита - новые интересы } \\
\text { «Инициатива снизу» } \\
\text { Заключение }\end{array}$ & Принята в номер: 25.09.2016 \\
\hline
\end{tabular}

Государственный институт искусствознания МК PФ; j_kononenko@inbox.ru

В статье выделяются несколько групп патронов мусульманской архитектуры в султанате Сельджуков Рума. В первой половине XIII в. государство смогло реализовать масштабную пропагандистскую программу, одним из инструментов которой стала «официальная сельджукская мечеть». Ослабление династии после монгольского вторжения привело к сокращению госзаказа и активизации частной строительной инициативы визирей и высших чиновников. К концу XIII в. основную группу заказчиков составили представители уммы - городская администрация, купцы, ремесленные гильдии, демонстрировавшие собственное благочестие и внимание к нуждам локальных общин. Каждая из групп патронов сосредоточилась на близких ей общественных интересах, сумела найти в строительном заказе собственную нишу и способствовала формированию новых типов и композиций мусульманской архитектуры.

Ключевые слова: благотворительность, архитектурный патронат, общественная иницчиатива.

\begin{tabular}{|c|c|}
\hline UDC 297.1: 323.28 & The content of the article \\
\hline $\begin{array}{l}\text { DOI: } 10.21779 / 2077- \\
8155-2016-7-4-58-68\end{array}$ & $\begin{array}{l}\text { Introduction } \\
\text { «Monumental propaganda» of the Seljuks of Rum } \\
\text { The new elite - new interests }\end{array}$ \\
\hline E.I. Kononenko ${ }^{* *}$ & $\begin{array}{l}\text { «nitiative from below» } \\
\text { Conclusion }\end{array}$ \\
\hline
\end{tabular}

\section{Information about the article}

Received: 25.07.2016

Submitted for review: 26.07.2016

Review received: 29.08.2016

Accepted for publication:

25.09.2016

\title{
"Deeds are Derived from the Building": the Range of the Patrons of Anatolian Seljuk Muslim Architecture
}

\footnotetext{
* Кононенко Евгений Иванович - ученый секретарь сектора искусства стран Азии и Африки, Московский государственный институт искусствознания, кандидат искусствоведения.

** Evgeny Ivanovich Kononenko- academic secretary at the Sector of Art of Asia and Africa at Moscow State Institute of Art Studies, candidate of art criticism.
} 
Кононенко Е.И. «Благодеяния происходят из строительства»: круг заказчиков сельджукской мусульманской архитектуры Анатолии // Исламоведение. 2016. Т. 7. № 4. С. 58-68

State Institute of art MK of the Russian Federation; j_kononenko@inbox.ru

The article deals with some groups of Muslim architectural patrons in the sultanate of the Seljuk of Rum. The government managed to realize a wide propagandist program in the first half of the $13^{\text {th }}$ century, and one of the main tools was the official Seljuk mosque. The decline of the dynasty after the Mongol invasion resulted in the reductionof the government order and the rise in the construction activity of viziers and governors. Till the end of the $13^{\text {th }}$ century, the main group of patrons consisted of umma members - city administration, traders, craft guilds, who demonstrated their own piety and understanding of the needs of the local community. Every group of the patrons made their social interests the main goal and managed to find their own niche in the construction work, thus contributing to the development of the new types and compositions of Muslim architecture.

Keywords: charity, architectural patronage, public initiative

\section{Введение}

Султанат Сельджуков Рума - государство, возникшее в конце XI в. после тюркского завоевания Анатолии. К концу XII в. султанат подчинил себе соседние княжества и на несколько десятилетий стал одной из наиболее могущественных политических сил мусульманского Востока.

Современники высоко ценили строительную деятельность сельджукских правителей, заинтересованных в репутации покровителей ислама. Так, нашедший приют при дворе султана в столичной Конье беженец из разоренного монголами Ирана Наджм адДин ар-Рази писал: «И, слава Аллаху, в этой стране правит падишах из потомков рода Сельджуков $<\ldots>$ Те благодеяния и благодетельства, что были в счастливые времена этих падишахов, следующих религии и заботящихся о ней, происходят из <..> строительства различных медресе и ханак, мечетей и минбаров, соборных мечетей, мостов, рибатов, больниц и других благих мест» [2, с. 15].

Однако после поражения от монголов при Кёсе-даге (1243 г.) сохранившие номинальную власть сельджукские правители уже не могли позволить себе масштабные строительные проекты. На протяжении второй половины XIII в. в Анатолии выдвигаются новые группы заказчиков, не только нашедшие новые ниши в благотворительном архитектурном патронате, но и способствовавшие обогащению типологии мусульманских сооружений.

\section{«Монументальная пропаганда» Сельджуков Рума}

В первой трети XIII в. султаны Иззеддин Кейкавус I и Алаеддин Кейкубад I, проявившие себя прекрасными администраторами, превратили Румский султанат в могущественную и богатую мусульманскую державу [11, с. 245]. В историографии правление Сельджуков Рума часто становится точкой отсчета для анализа особенностей мусульманской культуры Анатолии, что свидетельствует как о высоком художественном качестве сохранившихся произведений, так и об эффективности проспективной политической риторики, инструментом которой эти памятники являлись $\left[6\right.$, с. $43 ; 1$, с. 3-6] ${ }^{1}$.

Сельджукские султаны зарекомендовали себя как активные строители дорог, городов, караван-сараев, крепостей и дворцов; однако наиболее показательными, «резонансными» оказались возводимые ими мечети. Перестройка главной мечети в цитадели

${ }^{1}$ См. подробнее: Кононенко Е.И. Анатолийские мечети Великих Сельджуков: архитектурные и политические ориентиры // Искусствознание. - 2015. - № 3-4. - С. 141-143. 
Kononenko E.I. "Deeds are Derived from the Building": the Range of the Patrons of Anatolian Seljuk Muslim Architecture // Islamovedenie. 2016. V. 7. № 4. P. 58-68

Коньи привела к созданию эклектичного здания Алаеддин-джами $[8 ; 19]^{1}$, которое было воспринято как образец. В соответствие ему (на уровне архитектурных цитат) пытались привести перестраиваемые соборные мечети - улу-джами ${ }^{2}$ - бывших столиц анатолийских княжеств (Кайсери, Эрзерум), а также вновь закладываемые культовые здания в крупных городах султаната (Нигде, Малатья, Дивриги). Все они приобрели общие черты - продольно-базиликальную планировку молитвенного зала с расширенным центральным нефом, акцентированную купольную михрабную ячейку, оформленную как павильон-максура, отказ от внешнего двора в пользу световой ячейки в интерьере.

Общность композиции культовых зданий, возводимых по монаршему заказу в наиболее значимых центрах государства, свидетельствует о продуманной строительной программе, направленной на визуальное закрепление представлений о единстве центральной власти и демонстрировавшей покровительство исламу. Таким образом, в культовом зодчестве - наиболее репрезентативном кластере средневековой архитектуры - сельджукские султаны реализовали своеобразный «план монументальной пропаганды». Этому плану следовали как архитекторы, осуществлявшие строительство мечетей непосредственно под патронатом султана, так и мастера, работавшие по заказам членов монаршей семьи и вассальных князей. Примером тому служат, по меньшей мере два памятника.

В знаменитом своей декоративной программой комплексе Улу-джами в Дивриги (1228), объединившем мечеть и больницу-шифахане и построенном сохранившей номинальную власть династией Менгучагидов, упоминание сюзерена в строительной надписи на фасаде сведено к элементу датировки: «В дни правления великого султана Алаеддина Кейкубада, сына Кейхосрова...» [18, с. 183], а на портале больницы сюзерен вообще не упоминается - возможно, на благотворительное учреждение не распространялись требования политической риторики. Тем не менее молитвенный зал в Дивриги следует композиции «официальной сельджукской мечети», отличаясь лишь количеством нефов и акцентированием поперечной оси с помощью бокового входа.

Вторым примером является комплекс Хуанд-хатун в Кайсери (1238), построенный по заказу одной из жен Алаеддина Кейкубада I, ставшей на короткий период фактическим регентом до совершеннолетия его сына и преемника Гиясаддина Кейхосрова II. В состав благотворительного комплекса вошли мечеть, медресе, мавзолей, хамам (бани) и, вероятно, имарет (благотворительная столовая). Надписи на фасадах здания позволяют предположить, что возведение комплекса было начато еще при жизни Алаеддина Кейкубада, но основные работы относятся уже ко времени правления его сына, что, собственно, и позволило одной из младших жен султана использовать открывшиеся возможности матери правителя и акцентировать свою роль покровителя искусств. В новой мечети вне цитадели Кайсери, превосходившей по размерам все прежние постройки, использована та же композиция с акцентированием центрального нефа, купольной максурой в увеличенной михрабной ячейке и превращением центра интерьера в аналог внутреннего двора.

Единство планировочных и композиционных решений мечетей, как перестроенных, так и вновь возводимых по высокому государственному заказу, свидетельствует о наличии определенной строительной программы. Сельджукский патронат был направ-

1 Подробнее см.: Кононенко Е.И. Мечеть Алаеддина в Конье: «переосмысление» и архитектурные реалии // Иран-наме. - 2015. - № 3-4 (35-36). - С. 336-356.

${ }^{2}$ См.: Кононенко Е.И. Улу-джами: история, особенности, возможности // Исламоведение. 2016. - № 2. - С. 73-83. 
Кононенко Е.И. «Благодеяния происходят из строительства»: круг заказчиков сельджукской мусульманской архитектуры Анатолии // Исламоведение. 2016. Т. 7. № 4. С. 58-68

лен на визуализацию идей унификации и нормативного «огосударствления культуры», инструментом чего прекрасно послужила именно культовая мусульманская архитектура, прежде всего большие городские мечети.

Однако после поражения от монголов при Кёсе-даге (1243) династия Сельджуков Рума перестала быть крупнейшим патроном архитектурных проектов, в первую очередь из-за отсутствия средств [16, с. 5]. Мечети, возводимые самими султанами или членами их семей, например Улу-джами в Девели (1282), Ахмет-паша-джами в Токате (1287), - не «госзаказ», а плод личной инициативы и личного финансирования, и эти памятники уже не носили характера какого-либо «норматива». Композиция «официальной сельджукской мечети» вдохновила на перестройку караван-сараев в молитвенные здания и на возведение нескольких новых построек (Хаджи Кылыч-джами в Кайсери, Улу-джами в Байбурте), однако речь в данных случаях должна идти лишь об инерции авторитетного архитектурного типа.

Последним «всплеском» сложившейся сельджукской композиции стала Эшрефоглу-джами в Бейшехире (1297-99), заложенная вассальной династией Эшрефидов незадолго до полного распада Сельджукского государства [14]. Здание представляет собой 7-нефную базилику с выделенной купольной максурой, световым колодцем в центре интерьера над глубоким колодцем-ледником (тур. karlik) и декорировано роскошным «сельджукским порталом» ${ }^{1}$, однако, в отличие от памятников «золотого века» султаната, имеет деревянные перекрытия, опирающиеся на деревянные же столбы. Бейшехирская мечеть демонстрирует, с одной стороны, хорошее усвоение практики сельджукской архитектуры, а с другой - неспособность конийских султанов осуществлять масштабные проекты и переход инициативы архитектурного патроната к правителям пограничных княжеств, ставших ядром формирующихся независимых бейликов.

\section{Новая элита - новые интересы}

Превращение Сельджуков Рума в вассалов ильханов привело к изменению системы архитектурного заказа. Место султанов в патронате занял новый круг заказчиков верхушка сельджукской и монгольской администрации. Изменился и сам заказ: во II половине XIII в. его объектом стали прежде всего небольшие квартальные мечети, компактные медресе, дервишеские обители и благотворительные сооружения (больницы, караван-сараи).

Монгольские правители не были заинтересованы ни в ослаблении и разорении Анатолии, ни в разрушении ее административного аппарата, не имевшего альтернативы и исправно обеспечивавшего монголов данью. Некоторые ильханы и высшие чиновники ильханата (например, принявший ислам ильхан Ахмед Текудер и великий визирь Шемседдин Джувейни ${ }^{2}$ ) были заинтересованы в укреплении именно мусульманской общины (часто в противовес христианам и иудеям), но их интересы были сосредоточены в первую очередь в Иране и Азербайджане [3, с. 228-259]. На подконтрольных же Сельджукам Рума землях выдвинулась группа высших чиновников - Джелаледдин

1 О знаковой роли порталов как выражения претензий на власть см.: Кононенко Е.И. «Сельджукский портал»: архитектурная декорация как средство политической риторики // Вестник СПбГУ. Серия 15. Искусствоведение. - 2015. - Вып. 1. - С. 133-143.

2 Шемседдин (Шамс ад-Дин) Джувейни два десятка лет был главным визирем (сахиб-диван) ильханов, с 1278 г. - фактическим наместником Анатолии. Прославился как меценат; ему, в частности, посвящал стихи Саади. Неоднократно обвинялся в казнокрадстве; в 1284 г. казнен по подозрению в государственной измене. 
Kononenko E.I. "Deeds are Derived from the Building": the Range of the Patrons of Anatolian Seljuk Muslim Architecture // Islamovedenie. 2016. V. 7. № 4. P. 58-68

Каратай $^{1}$, Муинеддин Сулейман Перване ${ }^{2}$, Фахреддин Али ${ }^{3}$, умело совмещавших защиту интересов как номинальных правителей разделенного государства, так и их сюзеренов, при этом конкурировавших друг с другом и стремившихся упрочить свое положение, в т. ч. прибегая к практике архитектурного патроната [10, с. 134-137, 280-291; 12 , с. $60-62 ; 13$, с. $3-57 ; 22$, с. $312-315]$.

Необходимо отметить, что, хотя великие визири имели реальную власть и достаточные средства для строительства, они, очевидно, не претендовали на возведение больших городских мечетей, деликатно оставляя эту нишу султанам и сосредоточившись на патронате медресе и загородных мечетей. Весьма возможно, что на этот счет действовало некое неписаное правило, определявшее «статусность» и размер построек (во всяком случае, мечетей), приличествующих определенным категориям заказчиков архитектуры [13, с. 9].

В отличие от школ Ирана и Средней Азии, встроенных в полифункциональные комплексы [5, с. 260-261], в Анатолии медресе становятся отдельными архитектурными объектами, нуждавшимися не только в соответствующей функциям планировке, но и в необходимо разветвленной типологии и архитектурном оформлении, способном, в частности, служить инструментом политической риторики; они стали самостоятельным объемом и «обрели наружность» [4, с. 277].

В Анатолии на протяжении всего XIII в. возводились школы, планировка которых следовала заимствованной из Ирана структуре айванного медресе с открытым двором, вокруг которого формируются жилые помещения, причем этот тип был весьма востребован в репрезентативном частном заказе (Шифайе в Сивасе, ставшее усыпальницей султана Иззеддина Кейкавуса I; медресе Чифте Минаре в Эрзеруме, финансировавшееся Худавенд Ханде-хатун, дочерью Алаеддина Кейкубада; Гёк-медресе в Амасье, возведенное по инициативе Муинеддина Перване; сивасские Гёк-медресе, построенное Фахреддином Али, Буруджийе - заказ визиря Музаффера Буруджерди, медресе Чифте Минаре, заложенное Шемседдином Джувейни, причем, судя по строительной надписи, «единолично», без упоминания сюзеренов) [7, с. 117; 12, с. 71-72].

Однако во второй половине XIII в. в центре Румского султаната был разработан новый архитектурный тип учебных заведений - компактные медресе, как правило, одноэтажные, с заменившим двор купольным залом, окруженным учебными и жилыми помещениями. К лучшим памятникам этого типа относятся конийские школы Бюйюк Каратай (1252) и Индже минаре (1264-1265). Оба здания построены возле цитадели Коньи и дворца сельджукских султанов, что демонстрирует высокий официальный статус этих школ, и возведены по заказу высших сановников, последовательно занимав-

${ }^{1}$ Джелаледдин (Джалал ад-Дин) Каратай ибн Абдаллах (ум. 1254) - грек по происхождению, вольноотпущенник Алаеддина Кейкубада I, незадолго до Кёсе-дага назначен Гиясаддином Кейхосровом II Великим визирем. После признания вассалитета Сельджуков Рума был фактическим правителем султаната.

${ }^{2}$ Муинеддин (Муин ад-Дин) Сулейман Перване - зять султана Рукнеддина Кылыч-Aрслана IV, формальный регент при малолетнем Кейхосрове III. Создал свой удел с центром в Синопе, где его сыновья образовали местную династию Перванеоглу. Казнен монголами в 1277 г.

3 Сахип Ата Фахреддин (Фахр ад-Дин) Али ибн аль-Хусейн ибн Абу Бакр (ум. 1289) возвысившийся после Кесе-дага сельджукский администратор, Великий визирь султаната Рума (после смерти Перване), прославленный покровитель торговли и образования, меценат; его сыновья попытались создать независимый удел в Афьоне, подчинившийся бейлику Гермиян. 
Кононенко Е.И. «Благодеяния происходят из строительства»: круг заказчиков сельджукской мусульманской архитектуры Анатолии // Исламоведение. 2016. Т. 7. № 4. С. 58-68

ших пост Великого визиря, - Джелаледдина Каратая и Фахреддина Али, не испытывавших недостатка ни в амбициях, ни в средствах, и уже поэтому от исполнения этих заказов правомерно ожидать предельного качества, на какое была способна позднесельджукская архитектура. В подчеркнутом соседстве двух медресе, одно из которых было преимущественно астрономической школой, а другое - училищем хадисоведов $($ $а р-y л ь-х а \partial и c)$, можно усмотреть проявление определенной ревности со стороны преемника Каратая на посту Великого визиря.

Правда, поколения Каратая, Фахреддина Али и Перване оказались последними крупными заказчиками архитектурных сооружений у их преемников также не оказалось ни средств, ни амбиций, которые имело бы смысл выражать этими средствами $[12$, с. 65-66].

Разработка в Анатолии модели маленького медресе с перекрытым центральным двором сопоставима и со сложением здесь же лишенной двора зальной мечети, соответствовавшей климатическим условиям и численности уммы. Большинство таких молитвенных зданий - квартальных или базарных мечетей (месджит) - возводились по заказу обеспеченных представителей «среднего класса»: провинциальных чиновников, купцов, потомков местных династов. Важно, что такие постройки, в отличие от «государственных» мечетей, не только обеспечивали поминание основателей, но и в ряде случаев служили местом их упокоения и увековечивали их имена. Таковы, например, Хаджи Феррах-месджит и Эрдемшах-месджит в Конье, Акшебе Султан-месджит в цитадели Алании, заказанная Эминуддином Хаджи Хасаном ибн Мухтесибом Гюдюк Минаре-месджит в Акшехире и акшехирская же Кючюк Айясофия-месджит, связываемая с неким Шемседдином Хасаном (само ее название «маленькая св. София» указывает на происхождение от христианской постройки) [7, с. 66-71].

Практически все месджиты имеют одинаковую планировку - квадратный в плане перекрытый куполом молитвенный зал, часто с входом в углу, иногда небольшой сводчатый портик или пронаос в антах, в некоторых случаях дополнительное помещение гробницы заказчика. «Аполитичность» и ординарность подобных памятников позволили им избежать «идеологических» перестроек, а простота архитектуры уберегла от зачастую еще более разрушительных ремонтов. Более того именно этот тип, по конструкции и композиции схожий с небольшими византийскими церквями, получил распространение на северо-западе Малой Азии и во многом повлиял на формирование османской мечети.

\section{«Инициатива снизу»}

Важную группу памятников культовой архитектуры второй половины XIII в. составляют здания, построенные по «инициативе снизу» на деньги самих мусульманских общин или их отдельных представителей (провинциальной знати, купеческих гильдий, ремесленных объединений), неожиданно оказавшихся весьма активными заказчиками.

Ослабление центральной власти и идеологии «государственного ислама» привело к росту влияния религиозных организаций - суфийских тарикатов, дервишеских общин, религиозно-ремесленных объединений. В Анатолию из Ирана, Сирии и Египта устремлялись проповедники (баба) самых разных идей, как исключительно мистикотеологических, так и социально-реформаторских, неминуемо приобретавших религиозную окраску. Во II половине XIII в. на волне почитания вероучителей в городах Анатолии появляется своеобразный тип мечети, служившей прежде всего обителью дервишей, - текке. 
Kononenko E.I. "Deeds are Derived from the Building": the Range of the Patrons of Anatolian Seljuk Muslim Architecture // Islamovedenie. 2016. V. 7. № 4. P. 58-68

Такие обители строились как резиденции почитаемого духовного лица или группы лиц, например суфиев определенного тариката, однако они служили как жилищем или гостевым домом, так и местом проведения ритуальных церемоний, диспутов, занятий с духовными учителями, и, безусловно, коллективных молитв, в которых принимали участие не только «постояльцы», но и жители окружавшего квартала и купцы из соседних лавок и бедестенов (крытых базаров). Тем самым текке выполненяли функции квартальных и даже городских мечетей как центров религиозной и социальной активности. Маленькие текке сплачивали духовных лидеров, странствующих дервишей, местную элиту, ремесленные братства, торговцев, горожан, иммигрантов [20, с. 11].

Строительство текке было для патронов, представителей провинциальной знати или торговой элиты, правительственных чиновников, прекрасной возможностью почтить уважаемых духовных лидеров, продемонстрировать религиозное благочестие и увековечить свое имя на портале культового здания. Возведение и содержание небольших «приютов» обходилось намного дешевле, нежели крупных городских мечетей или медресе, а политический резонанс от поддержки влиятельных групп суфиев или дервишей, к которым прислушивались горожане, был иной раз для амбициозных заказчиков неизмеримо выше, чем от фетв имамов или подготовки учеников медресе [21, c. 39-41].

Текке оказались точками социальной консолидации, альтернативой «государственному исламу» и официальным медресе. К концу XIII в. небольшие текке каппадокийских городов, дополняемые целым рядом помещений и даже отдельных зданий, превращаясь в многофункциональные комплексы и формируя вокруг себя необходимую инфраструктуру [20, с. 48, 52, 57-59, 97-100], децентрализовали сельджукские города и в качестве градостроительных ячеек оказались предтечами османских куллие.

Большинство зданий текке было перестроено, однако на основании реконструкций можно заключить, что непременным элементом всех обителей был квадратный зал, перекрытый куполом, использовавшийся для всех публичных мероприятий. Именно купольный зал, вокруг которого формировались жилые комнаты, хозяйственные помещения и в который открывались имеющиеся в некоторых комплексах сводчатые айваны, роднит планировку текке с квартальными мечетями (месджит). Следует отметить, что симметричное расположение боковых келий относительно центральной оси в некоторых обителях (например, в текке Шамс ад-Дин ибн Хусейн в Токате) близко к планировке раннеосманских мечетей «типа Бурсы» и должно было облегчать выбор образца при последующей перестройке обителей в городские мечети.

Однако к концу XIII в. в сельджукской Анатолии появляется особая группа заказчиков мусульманской архитектуры, способных проявлять и реализовывать «инициативу снизу», - гильдии ремесленников, имевшие, подобно суфийским тарикатам, свой устав, администрацию, «филиалы» в разных городах, наладившие тесную связь между «ячейками». Особое место среди них занимало Ахийат аль-Фитйан (тур. Ахилик «Братство молодых»), или ахи.

Ячейки $а х и$ выросли из городских гильдий специализированных ремесленников, срослись с дервишескими орденами и под влиянием проповедей о социальном переустройстве превратились в замкнутые группы, которые можно определить как религиозновоинские братства, со своими идеологией, иерархией, организационной структурой и в условиях явной слабости официальных властей на рубеже XIII-XIV вв., взятыми на себя административными, контрольными и милицейскими функциями. Оставаясь подмастерьями-«цеховиками», члены ахи обучались владению оружием и оказались спо- 
Кононенко Е.И. «Благодеяния происходят из строительства»: круг заказчиков сельджукской мусульманской архитектуры Анатолии // Исламоведение. 2016. Т. 7. № 4. С. 58-68

собны к обороне городов от туркменских набегов. Показав себя организованной силой, с которой приходилось считаться, региональные отделения $а x и$ в ряде случаев могли успешно осуществлять городское самоуправление, в т. ч. контроль за торговыми операциями, распределение миграционных потоков, выстраивание отношений с немусульманским населением и строительство культовых сооружений [9, с. 28-48; 10; с. 335341].

Ярким примером архитектурного патроната ахи является мечеть Ахи Шерафеддин-джами (известная как Арсланхане, 1289-1290), расположенная на южном склоне холма цитадели Анкары. Официальное название комплекса свидетельствует о связи заказчиков с братством ахи, «бытовое» же название - «Львиный дом» мечеть получила за каменные фигуры львов, использованные в кладке находящегося рядом текке; в комплекс построек входила и гробница. С одной стороны, располагаясь за городской стеной, комплекс Арсланхане использовался и как дервишеская обитель, и как место для собраний «Братства молодых» [15, с. 136; 17]. Типологически здание является довольно просторной городской мечетью с каменными стенами довольно грубой кладки (некоторые плиты взяты из римских и византийских построек) и деревянным перекрытием на деревянных же столбах. Непривычно высокий для сельджукской архитектуры молитвенный зал по трем стенам (кроме северной) сделан двусветным, при этом над верхним рядом проемов на боковых стенах под самым потолком сделаны по два дополнительных световых проема.

Городские мечети с деревянными конструкциями в конце XIII в. не были редкостью в сельджукской архитектуре: таковы, например, Улу-джами в Байбурте (12831298) и Эшрефоглу-джами в Бейшехире (1297-99) [14], которые, однако, строились вполне легитимными официальными заказчиками (представителями династии Сельджуков Рума и вассалами-Эшрефидами) и с воспроизведением черт «официальной сельджукской мечети» (максура, световой колодец); в других случаях (Улу-джами Афьона, Сиврихисара, Айяса) «деревянные мечети» являются именно «соборными» молитвенными зданиями. Несмотря на конструктивную близость, анкарская Арсланхане не принадлежит ни к одной из этих групп: ее интерьер не расчленен в плане - это гипостильный зал без выделения максуры, без светового колодца; таким образом, архитекторы постройки, по размерам вполне соответствовавшей большим городским мечетям, отказываются от следования рассмотренной сельджукской модели. С другой стороны, вынесение здания за ворота цитадели свидетельствует против его общедоступности.

Спорным остается вопрос о хронологии и синхронности построек комплекса Ахи Шерафеддин: была ли мечеть построена рядом с уже существовавшим текке или же обитель возникла рядом с мечетью. Однако в любом случае налицо связь большой мечети с $a x u$, и для разговора об архитектуре мечети не важно, было ли братство $а x и$ непосредственным заказчиком или лишь «пользователем» культового комплекса, возведенного не принадлежавшим к братству заказчиком. Размеры Арсланхане демонстрируют не только влияние анкарской ячейки ахилик, но и социальную востребованность большой мечети вне цитадели, а нетипичность конструкции деревянной гипостильной мечети позволяет говорить о формировании к концу XIII в. в «низовом» архитектурном заказе ярко выраженной альтернативы и модели большой «официальной» мечети, и маленькому сельджукскому квартальному месджиту. 
Kononenko E.I. "Deeds are Derived from the Building": the Range of the Patrons of Anatolian Seljuk Muslim Architecture // Islamovedenie. 2016. V. 7. № 4. P. 58-68

\section{Заключение}

В анатолийской архитектуре XIII в. возведение построек, предназначенныХ для нужд уммы, неизменно воспринималось как средство демонстрации благочестия. Однако несколько исторических этапов существования Конийского султаната позволяют говорить и об изменении круга основных заказчиков мусульманской архитектуры, и о смене приоритетных архитектурных моделей.

В первые десятилетия XIII в., в эпоху золотого века Сельджуков Рума благодаря унифицированному госзаказу и использованию архитектуры как инструмента политической риторики была сформирована модель «официальной сельджукской мечети», распространившаяся из столичной Коньи в центры подчиненных территорий. Эта же модель, воспринятая как норматив, посильно использовалась и в строительной практике вассальных княжеств. Авторитет государственности Сельджуков Рума, закрепленный в монументальной культовой архитектуре, оказался столь высок, что его инерции, выраженной в щедром архитектурном цитировании образцов, хватило и на патронат могущественных визирей, и на заказы в приграничных областях (Байбурт, Бейшехир), и на необходимую строительную активность «общественных организаций» типа братства $a x u$. Речь должна идти о весьма бережном сохранении закрепленных в домонгольских сельджукских памятниках визуальных элементов государственной парадигмы.

Явное ослабление Сельджуков Рума после монгольского нашествия привело к выделению высокого частного заказа. Являясь на протяжении почти всей второй половины XIII в. наиболее представительной группой патронов мусульманской архитектуры, визири Рума (Каратай, Перване, Фахреддин Али, Джувейни) не претендовали на возведение больших городских мечетей. Они предпочитали реализовывать свой благотворительный патронаж прежде всего в медресе и в них же встраивать свои усыпальницы. Анатолийские медресе превратились в отдельно стоящие здания, стали самостоятельными объектами, приобрели фасады, отмеченные порталами и минаретами, и, организуя вокруг себя пространство и конкурируя в городской панораме с большими мечетями, стали «точками конденсации» застройки.

К концу XIII в. в архитектурный патронаж включились новые группы заказчиков, как индивидуальных (купцы, городские чиновники), так и коллективных (религиозные объединения), обычно обладавшие более скромными возможностями, но адресно нацеленные на нужды «конечных пользователей» - тарикатов, дервишеских и ремесленных братств, городских мусульманских общин в целом.

Каждая группа анатолийских патронов сосредоточивалась на разработке определенных типов архитектурных сооружений: унифицированному госзаказу соответствовали большие улу-джами, с ослаблением монаршего патроната практически исчезнувшие на столетие; обеспеченный частный заказ вызвал к жизни тип компактного зального медресе; мусульманское строительство привело к разработке типов квартальных мечетей-месджитов и обителей-текке. Необходимо указать, что все типы мусульманской архитектуры, появившиеся в XIII в., оказались базой для развития зодчества в последующие два столетия на территории анатолийских бейликов и Османского государства.

Таким образом, ослабление роли государства в мусульманском архитектурном патронате привело к расширению круга заказчиков, неизменно вдохновлявшихся представлениями о строительной инициативе как о достойном деянии и способе достижения благодати. Освобождение ниши мусульманского строительного заказа от строгой официальной регламентации и унификации позволило включиться в этот процесс как общественным организациям, так и частным лицам, причем не только вельможным сановникам. Эти новые заказчики смогли рассчитать свои возможности и отказаться от конкуренции с государственной программой, несмотря на ее привлекательность и ре- 
Кононенко Е.И. «Благодеяния происходят из строительства»: круг заказчиков сельджукской мусульманской архитектуры Анатолии // Исламоведение. 2016. Т. 7. № 4. С. 58-68

зультативность; демонстрируя как собственное благочестие, так и способность удовлетворить запросы конкретных общин, находя возможности обходиться собственными средствами, они посильно сосредоточились на «малых формах» архитектуры. В конечном итоге подобное «распыление форм» привело к формированию новых архитектурных композиций, определивших развитие мусульманского зодчества Анатолии.

\section{Литература}

1. Миллер Ю. Искусство Турции. - М.-Л.: Искусство, 1965.

2. Наджм ад-Дин Дайа ар-Рази. Лестница в Небо: наука для влюбленных. - М.: Ансар, 2008.

3. Петрушевский И.П. Иран и Азербайджан под властью Хулагуидов (1256-1353) // Татаро-монголы в Азии и Европе. - М.: Наука, 1977.

4. Стародуб T.X. Сокровища исламской архитектуры. - М.: Белый город, 2004.

5. Хмельницкий $C$. Между Саманидами и монголами. Архитектура Средней Азии XI - начала XIII в. Ч. 1. - Берлин - Рига: Gamajun, 1996.

6. Arseven G.E. L'Art Turc depuis son origine jusqu'a nos jours. - Istanbul: Devlet Basimevi, 1939.

7. Aslanapa O. Turk Sanati. D. I-II. - Istanbul: Kervan, 1984.

8. Asutay-Effenberger $N$. Konya Alaeddin camisi yapim evreleri uzerine Düşünceler. Middle East Technical University // Journal of Faculty of Architecture. - 2006. - № 2.

9. Baer G. The Administrative, Economic and Social Functions of Turkish Guilds // International Journal of Middle East Studies. - 1970. - Vol. 1, № 1.

10. Cahen $C$. Pre-Ottoman Turkey. A general survey of the material and spiritual culture and history c. 1071-1330. - N.Y.: Taplinger Publishing, 1968.

11. The Cambridge History of Islam. Vol. I a. - Cambridge: Cambridge University Press, 2008.

12. The Cambridge History of Turkey. Vol. I: Byzantium to Turkey, 1071-1453. Cambridge: Cambridge University Press, 2009.

13. Crane H. Materials for the Study of Muslim Patronage in Saljuq Anatolia: The Life and Works of Jalâl-Al-Dîn Qaratâi. - Harvard: Harvard University Press, 1975.

14. Erdemir $Y$. Beyşehir Eşrefoğlu Süleyman Bey Camii ve Külliyesi. - Beyşehir: Beyşehir Vakfi, 1999.

15. Hayes $K$. The wooden hypostyle mosques of Anatolia. Mosque- and State-building under Mongol suzerainty. METU Graduate School of social sciences thesis. - Ankara, 2010.

16. Ögel S. The Seljuk Face of Anatolia: Aspects of the Social and Intellectual History of Seljuk Architecture // Foundation for Science, Technology and Civilization. - 2008. - № 842.

17. Öney G. Ankara Arslanhane Camii. - Ankara: Kültür bakanliği yayini, 1998.

18. Pancaroğlu $O$. The Mosque-Hospital Complex in Divriği: A History of Relations and Transitions // Anadolu ve Cevresinde ortaçağ. D. 3. - Ankara, 2009.

19. Redford S. The Alaeddin mosque in Konya reconsidered // Artibus Asiae. - 1991. Vol. 51, № 1-2.

20. Wolper E.S. Cities and Saints. Sufism and the Transformation of Urban Space in Medieval Anatolia. - Pennsylvania: Penn State University Press, 2003.

21. Wolper E.S. The Politics of Patronage: Political Change and the Construction of Dervish Lodges in Sivas // Muqarnas. - 1995. - Vol. XII.

22. Wolper E.S. Understanding the public face of piety: philanthropy and architecture in late Seljuk Anatolia // Mesogeios. - 2005. - № 25. - 2 .

\section{References}


Kononenko E.I. "Deeds are Derived from the Building": the Range of the Patrons of Anatolian Seljuk Muslim Architecture // Islamovedenie. 2016. V. 7. № 4. P. 58-68

1. Miller Y. Iskusstvo Turtsii. [The Art of Turkey]. Moscow-Leningrad: Iskusstvo, 1965 (In Russian).

2. Nadjm ad-Din ar-Razi. Lestnitsa v Nebo: Nauka dl'a vlublennyh [The Ladder to Heaven: Science for the Inamored] [Mirsad al-Ibad]. - Moscow: Ansar, 2008 (In Russian).

3. Petrushevskiy I.P. Iran i Azerbaijan pod vlast'u Hulaguidov (1256-1353) [Iran and Azerbaijan under Hulaguids, 1256-1353]. Tataro-mongoly v Azii i Evrope [Tatar-Mongols in Asia and Europe]. - Moscow: Nauka, 1977 (In Russian).

4. Starodub T. Sokrovischa islamskoy arhitektury [The Treasures of Muslim Architecture]. Moscow: Bely gorod, 2004 (In Russian).

5. Khmelnitsky S. Mezhdu Samanidami i mongolami. Arhitektura Sredney Azii XInachala XIII vv. [Between the Samanid Dynasty and the Mongols. The Architecture of Middle Asia of the $11^{\text {th }}$ - Early $13^{\text {th }}$ Centuries]. Pt. 1. - Berlin-Riga: Gamajun, 1996 (In Russian).

6. Arseven G.E. L'Art Turc depuis son origine jusqu'a nos jours. - Istanbul: Devlet Basimevi, 1939.

7. Aslanapa O. Türk Sanati. D. I-II. - Istanbul: Kervan, 1984.

8. Asutay-Effenberger N. Konya Alaeddin camisi yapim evreleri uzerine Düşünceler. Middle East Technical University // Journal of Faculty of Architecture. 2006. № 2.

9. Baer G. The Administrative, Economic and Social Functions of Turkish Guilds. International Journal of Middle East Studies. 1970. Vol. 1, № 1.

10. Cahen C. Pre-Ottoman Turkey. A general survey of the material and spiritual culture and history c. 1071-1330. - N.Y.: Taplinger Publishing, 1968.

11. The Cambridge History of Islam. Vol. I a. - Cambridge: Cambridge University Press, 2008.

12. The Cambridge History of Turkey. Vol. I: Byzantium to Turkey, 1071-1453. Cambridge: Cambridge University Press, 2009.

13. Crane H. Materials for the Study of Muslim Patronage in Saljuq Anatolia: The Life and Works of Jalâl-Al-Dîn Qaratâi. Harvard: Harvard University Press, 1975.

14. Erdemir Y. Beyşehir Eşrefoğlu Süleyman Bey Camii ve Külliyesi. - Beyşehir: Beyşehir Vakfi, 1999.

15. Hayes K. The wooden hypostyle mosques of Anatolia. Mosque- and State-building under Mongol suzerainty. METU Graduate School of social sciences thesis. Ankara, 2010.

16. Ögel S. The Seljuk Face of Anatolia: Aspects of the Social and Intellectual History of Seljuk Architecture. Foundation for Science, Technology and Civilization. 2008. № 842.

17. Öney G. Ankara Arslanhane Camii. - Ankara: Kültür bakanliği yayini, 1998.

18. Pancaroğlu O. The Mosque-Hospital Complex in Divriği: A History of Relations and Transitions. Anadolu ve Cevresinde ortaçă̆. D. 3. Ankara, 2009.

19. Redford S. The Alaeddin mosque in Konya reconsidered. Artibus Asiae. 1991. Vol. 51. № $1-2$.

20. Wolper E.S. Cities and Saints. Sufism and the Transformation of Urban Space in Medieval Anatolia. Pennsylvania: Penn State University Press, 2003.

21. Wolper E.S. The Politics of Patronage: Political Change and the Construction of Dervish Lodges in Sivas. Muqarnas. 1995. Vol. XII.

22. Wolper E.S. Understanding the public face of piety: philanthropy and architectur 